\title{
CTRP3 alleviates cardiac ischemia/reperfusion injury via LAMP1/JIP2/JNK signaling pathway
}

\author{
Yanbin Song ${ }^{1,}$, Yunqing Zhang ${ }^{2,}{ }^{*}$, Zhaofei Wan ${ }^{3}$, Junqiang Pan ${ }^{4}$, Feng Gao ${ }^{1}$, Fei Li $^{1}$, Jing Zhou ${ }^{1}$, \\ Junmin Chen ${ }^{1}$ \\ ${ }^{1}$ Department of Cardiovasology, Yan'an University Affiliated Hospital, Yan'an 716000, China \\ ${ }^{2}$ Department of Pathology, Yan'an University Affiliated Hospital, Yan'an 716000, China \\ ${ }^{3}$ Department of Cardiology, The Second Affiliated Hospital of Xi'an Jiaotong University, Xi'an 710038, China \\ ${ }^{4}$ Department of Cardiology, Xi'an Central Hospital, Xi'an 710061, China \\ ${ }^{*}$ Equal contribution
}

Correspondence to: Yanbin Song; email: syb@yau.edu.cn

Keywords: ischemia/reperfusion injury, oxygen-glucose deprivation/reoxygenation, CTRP3, LAMP1, oxidative stress

Received: September 7, $2021 \quad$ Accepted: January 17, $2022 \quad$ Published: February 3, 2022

Copyright: (C) 2022 Song et al. This is an open access article distributed under the terms of the Creative Commons Attribution License (CC BY 3.0), which permits unrestricted use, distribution, and reproduction in any medium, provided the original author and source are credited.

\section{ABSTRACT}

Background: C1q/tumor necrosis factor-related protein 3 (CTRP3) has been reported to be a crucial regulator in myocardial infarction. Nevertheless, the potential molecular mechanism of CTRP3 in ischemia/reperfusion (I/R) injury remains largely unclear.

Methods: The cell model of myocardial I/R injury was established by oxygen-glucose deprivation/reoxygenation (OGD/R) of rat cardiomyocyte H9C2. Expression of CTRP3 and lysosomal-associated membrane protein 1 (LAMP1) was detected in H9C2 cells treated with oxygen-glucose deprivation/reoxygenation (OGD/R). H9C2 cells were transfected with overexpression plasmids of CTRP3 (pCDNA-CTRP3) and LAMP1 (pCDNA-LAMP1), or CTRP3 small interfering RNA (si-CTRP3) or/and pCDNA-LAMP1, and cell proliferation, apoptosis and oxidative stress were testified. Co-IP assay was performed to validate the relationship among CTRP3, LAMP1 and JIP2. The role of CTRP3 and LAMP1 in JIP2/JNK pathway was evaluated with Western blot assay. Furthermore, in vivo myocardial I/R injury model was constructed to investigate the effect of CTRP3.

Results: Overexpression of CTRP3 and LAMP1 both significantly promoted cell proliferation, inhibited apoptosis and the production of reactive oxygen species (ROS), malondialdehyde (MAD) and cardiac troponin (cTn-I), while silencing CTRP3 exerted the opposite effects, and LAMP1 overexpression reversed the effect of silencing CTRP3 on the aspects above. CTRP3 interacted with LAMP1, and both CTRP3 and LAMP1 bound with JIP2. SP600125 (JNK inhibitor) could restore the effects of CTRP3 or LAMP1 overexpression on the expression of JIP2 and phosphorylated-JNK ( $p-J N K)$, proliferation and apoptosis. Moreover, overexpression of CTRP3 improved cardiac $\mathrm{I} / \mathrm{R}$ injury in vivo.

Conclusion: CTRP3 alleviates cardiac I/R injury by elevating LAMP1 and activating JIP2/JNK signaling pathway, which may serve as a potential therapeutic target for I/R injury.

\section{INTRODUCTION}

Myocardial ischemia caused by coronary artery occlusion leads to increased loss of cardiomyocytes and is a main cause of elevated morbidity and mortality in myocardial infarction [1]. Reperfusion of ischemic myocardium is currently the common treatment for patients with acute myocardial infarction. However, the sudden restoration of blood flow may lead to the overproduction of reactive oxygen species (ROS), 
which promote oxidative stress, resulting in myocardial cell death after ischemia and aggravating myocardial injury [2]. Oxidative stress-induced myocardial injury is not only associated with the increase of ROS, but also related to the decline in the antioxidant defense system. Malondialdehyde (MDA) is a putative marker of lipid peroxidation and a common parameter determining increased free radical formation in post ischemic tissues [3]. Cardiac calponin I (cTn-I) is a contractile protein that is present only in cardiac muscle and serves as a specific biomarker of myocardial injury [4]. At present, the main methods to reduce myocardial $I / R$ injury are myocardial ischemia preconditioning (IP) and postischemia conditioning (PIC) [5]. However, IP and PIC are not easy to operate in the clinic. Therefore, it is necessary to explore new strategies for $\mathrm{I} / \mathrm{R}$ protection of cardiomyocytes to improve the clinical prognosis of patients with ischemic heart disease.

C1q tumor necrosis factor (TNF)-related protein-3 (CTRP3) belongs CTRP family and is a newly found group of proteins homologous to adiponectin (APN) collateral system [6]. It is mainly expressed in adipose tissues and is also found in the heart and liver [7,8]. CTRP3 has a variety of physiological functions, including reducing blood glucose [9], inflammation [10] and blood lipid [11]. Abnormal expression of CTRP3 is associated with the pathogenesis of many diseases including severe acute pancreatitis [12], diabetic retinopathy [13], and depression [14]. Recently, increasing evidence has indicated that CTRP3 plays an important role in many cardiovascular diseases. Ma et al. found that CTRP3 protected against diabetic cardiomyopathy via activation of the AMPK $\alpha$ pathway [15]. Chen et al. indicated that CTRP 3 could efficiently restrain inflammatory response and endothelial dysfunction in atherosclerosis [16]. Yi et al. demonstrated that CTRP 3 could promote angiogenesis and inhibit cell apoptosis in ischemic mouse heart [7]. Nevertheless, the involvement of CTRP3 in the pathogenesis of myocardial $\mathrm{I} / \mathrm{R}$ injury still poorly understood.

Lysosomal associated membrane protein 1 (LAMP1) is a glycosylated lysosomal membrane protein that belongs to lysosomal associated membrane protein family and could protect the lysosomal membranes from intracellular proteolysis [17]. Chen et al. suggested that Ubiquitin-like protein 4A (UBL4A) was low expressed in pancreatic ductal adenocarcinoma, while LAMP1 was positively correlated with UBL4A, and UBL4A exerted antitumor effects on autophagyrelated proliferation and metastasis in pancreatic ductal adenocarcinoma (PDAC) by upregulating LAMP1 [18]. Lamp1 positive astrocytes significantly suppress central nervous system inflammation by inducing $\mathrm{T}$ cell apoptosis [19]. Tanshinone IIA could improve heart function by upregulating LAMP1 expression and restoring autophagic flux [20]. Interestingly, cilostazol protected against myocardial ischemia by increasing LAMP1 expression [21]. Therefore, LAMP1 might function as a crucial regulator of myocardial I/R injury.

Herein, this study aimed to clarify the effects of CTRP3 and LAMP1 on myocardial $\mathrm{I} / \mathrm{R}$ injury and the underlying mechanisms, with a view to providing biomarkers for clinical prevention of myocardial I/R.

\section{METHODS}

\section{Cell culture and OGD/R model establishment}

The rat embryonic cardiomyocytes H9C2 were got from the cell bank of Shanghai Biology Institute, Chinese Academy of Science (Shanghai, China) and maintained in Dulbecco's modified Eagle medium (DMEM, Gibco, Grand Island, NY) supplemented with 10\% fetal bovine serum (FBS) in a humidified condition containing 5\% $\mathrm{CO}_{2}$ at $37^{\circ} \mathrm{C}$ (Thermo, Waltham, MA, USA). To establish the model of $\mathrm{I} / \mathrm{R}$ injury in vitro, cells were cultured in glucose-free DEME at $37^{\circ} \mathrm{C}$ in a hypoxic incubator $\left(94 \% \mathrm{~N}_{2}, 5 \% \mathrm{CO}_{2}\right.$ and $\left.1 \% \mathrm{O}_{2}\right)$ for $24 \mathrm{~h}$. After oxygen-glucose deprivation, cells were grown in complete medium at normal incubator $\left(95 \% \mathrm{O}_{2}, 5 \%\right.$ $\mathrm{CO}_{2}$ ) for $6 \mathrm{~h}$.

\section{Cell transfection}

CTRP3 and LAMP1 overexpression plasmid (pcDNACTRP3 and pcDNA-LAMP1), small interfering RNA targeting CTRP3 (si-CTRP3) and LAMP1 (si-LAMP1), as well as their negative control (vector and scramble) were constructed by Genepharma Biotech (Shanghai, China). H9C2 cells were transfected with above plasmid vector with lipofectamine 2000 (Invitrogen, Carlsbad, CA). After transfection for $48 \mathrm{~h}$, cells were given $\mathrm{OGD} / \mathrm{R}$ treatment, and then cells were collected for subsequent experiments.

\section{Quantitative real-time polymerase chain reaction (RT-qPCR)}

Total RNA from cells was extracted with TRIzol reagent (Invitrogen, Carlsbad, CA, USA) following the manufacturer's instructions. A TaqMan Reverse Transcription Kit (Qiagen, Valencia, CA) was used to reversely transcribe RNA to complementary DNA. RTqPCR was run on a 7000 ABI System by using SYBR Green PCR Kit (TaKaRa, Tokyo, Japan). GAPDH was used as an internal control. The relative quantitative expression was determined by using the $2^{-\Delta \Delta \mathrm{CT}}$ method. 
The primer sequences were described as follow: CTRP3, F, 5'-AGC GTC TCT GGG TTG TCT TG-3'; R, 5'-TGA GCT TCT GCC CCA ACA AA-3'; LAMP1, F, 5'-AGG CGG TGA GAT CTA GAC GA-3'; R, 5'AAG AAT AGT GTT GGC GGG GG-3'.

\section{MTT assay}

Cell viability was detected by using MTT assay. H9C2 cells were seeded at $5 \times 10^{3}$ cells/well on 96 -well plates. After $\mathrm{OGD} / \mathrm{R}$ treatment, cells were incubated with 20 $\mu \mathrm{L}$ of MTT solution $(0.5 \mathrm{mg} / \mathrm{mL})$ for $4 \mathrm{~h}$ at $37^{\circ} \mathrm{C}$. Then, the supernatant was removed, and $150 \mu \mathrm{L}$ of dimethyl sulfoxide were added to each well. The absorption was measured at $490 \mathrm{~nm}$ by using microplate reader (BioTek Instruments, Inc.).

\section{Ethynyl deoxyuridine (EdU) incorporation assay}

EdU detection was performed by using an EdU immunofluorescence staining kit (Ribobio, Guangzhou, China) according to the manufacturer's protocol. Sterilized slides were put into 24 well plates, and $\mathrm{H} 9 \mathrm{C} 2$ cells were seeded into each well at a density of $3 \times 10^{4}$ cells/well. Transfected cells were incubated with $20 \mu \mathrm{mol} / \mathrm{L}$ EdU reagent for $2 \mathrm{~h}$, washed twice with phosphate Buffer solution (PBS) and fixed with 4\% phosphate buffered paraformaldehyde for $15 \mathrm{~min}$. Subsequently, the cells were stained with $100 \mu \mathrm{L}$ of fresh Apollo reaction cocktail, and nuclei were stained with $100 \mu \mathrm{L}$ of Hoechst 33342. The percentage of EdU positive cells was counted by using fluorescence microscope (LEICA).

\section{Flow cytometry analysis}

Apoptosis of $\mathrm{H} 9 \mathrm{C} 2$ cells was detected by using the flow cytometry and a Annexin phycoerythrin/7aminoactinomycin D (V-PE/7-AAD) Apoptosis Detection Kit (Vazyme, Nanjing, China). After treatment, cells were collected and digested with trypsin without ethylenediamine tetraacetic acid. Then, the cells were washed three times with cold PBS and resuspended in $100 \mu \mathrm{L}$ of binding buffer. The cell suspension was incubated with $5 \mu \mathrm{L}$ of Annexin V-PE and $5 \mu \mathrm{L}$ of 7-AAD staining solution at room temperature for $10 \mathrm{~min}$ in a dark room. The apoptotic ratio of $\mathrm{H} 9 \mathrm{C} 2$ cells was assessed within $1 \mathrm{~h}$ by using flow cytometry (BD, Franklin Lakes, NJ, USA).

\section{Western blot analysis}

Total protein was extracted with RIPA lysis buffer. Protein concentration was determined by using the Bradford method. Equal amounts of protein were electrophoresed by $15 \%$ sodium dodecyl sulfatepolyacrylamide gel electrophoresis and transferred to polyvinyl difluoride (PVDF) membranes. The membranes were blocked in 5\% non-fat milk and then incubated with primary antibodies, including antiCTRP3 (1:1500, orb182796, Biorbty Ltd), anti-LAMP1 (1:1000, DF7033, Affinity), anti-JIP2 (1:750, DF3260, Affinity), anti-p-JNK (1:1000, AF3318, Affinity), antiJNK (1:1000, AF6318, Affinity) and anti-GAPDH (1:20000, 10494-AP, Proteintech) at $4^{\circ} \mathrm{C}$ overnight. The membranes were incubated with horseradish peroxidase (HRP)-conjugated goat anti-rabbit antibody (1:10000, 19003-1-AP, Proteintech). GAPDH was used as an internal control. The signals were detected by using an ECL kit (Pierce Biotech, Rockford, IL, USA). Subsequently, the protein bands were analyzed with Image J 1.43 software.

\section{Measurement of ROS and MDA production}

The production of ROS was detected by using Dichlorofluorescein diacetate (DCFH-DA) assay. Briefly, cells were incubated with $10 \mu \mathrm{mol} / \mathrm{L}$ DCFH$\mathrm{DA}$ at $37^{\circ} \mathrm{C}$ in the dark for $20 \mathrm{~min}$. Then, the cells were washed twice with PBS, and the fluorescence intensity was detected by using a fluorescence spectrophotometer (BioTek).

H9C2 cells were seeded in 96-well plates at a density of $1 \times 10^{4}$ cells/well. Myocardial tissues were homogenized and the supernatant was obtained. The activity of MDA was measured by using MDA activity kit (Nanjing Jiancheng Bioengineering Institute, Nanjing, China).

\section{Analysis of cardiac troponin (cTn-I) release}

H9C2 cell culture medium and myocardial tissue abrasive fluid were collected by centrifugation at $4^{\circ} \mathrm{C}$ for $15 \mathrm{~min}$. The concentration of cTn-I in the supernatant medium was determined by using enzymelinked immunosorbent assay kits (ELISA, Jiancheng, Nanjing, China) according to the manufacturer's instructions. The absorbance of the samples was measured at $450 \mathrm{~nm}$ with a standard microplate reader (BioTek Instruments, Inc.).

\section{Co-immunoprecipitation (Co-IP) assay}

Cells were lysed by utilizing Co-IP lysis buffer containing a protease inhibitor (Invitrogen, Carlsbad, USA). The lysates were collected and mixed with $2 \mu \mathrm{g}$ of primary antibody or immunoglobulin $\mathrm{G}$ (IgG). Then, the mixture was incubated with protein $\mathrm{A} / \mathrm{G}$ beads overnight at $4^{\circ} \mathrm{C}$. The beads were washed three times and boiled in loading buffer for 5 min. All samples 
were analyzed by Western blotting using various antibodies.

\section{Animals and in vivo myocardial I/R injury model}

C57BL/6J mice (weight 17-25 g) were purchased from Animal Laboratory of the Fourth Military Medical University and all mice were kept in a temperature and humidity-controlled room $\left(25 \pm 2^{\circ} \mathrm{C}, 60 \%-80 \%\right)$. Mice were randomly divided into 3 groups $(n=8$ mice of each group): Sham group, $\mathrm{I} / \mathrm{R}+$ lentiviral vectors (LVs) group and I/R+ CTRP3 overexpressed lentiviral vectors (LV-CTRP3) group. Three days before operation, mice myocardium was injected with LV-CTRP3 $(2 \mathrm{mg} / \mathrm{kg})$. Mice were anesthetized by inhalation of $2 \%$ isoflurane, and an oblique incision was made in their left chest wall skin to reveal the heart. The left anterior descending coronary artery was ligated with a polypropylene 6-0 suture. After $30 \mathrm{~min}$ occlusion, the sutures were loosened for $24 \mathrm{~h}$ to establish the myocardial I/R model. Sham operated mice underwent left chest wall incision surgery, but the left anterior descending coronary artery was not ligated. This study was approved by the ethics committee of the Affiliated Hospital of Yanan University. All animal experimental procedures were in accordance with the guide for the care and use of laboratory animals of the National Institutes of health.

\section{Echocardiographic assessment}

At the end of reperfusion, mice were immobilized on the experimental table, and ventricular function was examined by using an echocardiography system (Sequoia ACUSON, Siemens, Erlangen, Germany). Left ventricular end systolic diameter (LVESD), left ventricular end diastolic diameter (LVEDd), left ventricular end systolic volume (LVSV), and left ventricular end diastolic volume (LVDV) were measured and averaged over 3 consecutive cardiac cycles. As indicators of cardiac function, the left ventricular ejection fraction (LVEF) and left ventricular fractional shortening (LVFS) values were converted using the Simpson method with the following formulas: LVEF $=($ LVDV-LVSV $) /$ LVDV $\times 100 \% ;$ LVFS $=$ $($ LVDD-LVSD)/LVDD $\times 100 \%$. Experiments were performed 3 times and averaged.

\section{Infarct size determination}

Mice were anesthetized with inhalation of $2 \%$ isoflurane after $24 \mathrm{~h}$ of reperfusion, and the hearts were subsequently excised and frozen for $30 \mathrm{~min}$. Heart tissues were cut into 1-mm-thick sections and incubated with $1 \% 5$-triphenyltetrazolium chloride (TTC) at $37^{\circ} \mathrm{C}$ for $15 \mathrm{~min}$, with white being the infarct zone (INF) and red and white areas being the high-risk zone (AAR).
Infarct size was expressed by using the following formula: Infarct size $=\mathrm{INF} / \mathrm{AAR} \times 100 \%$.

\section{TUNEL staining}

TUNEL assay was used to detect apoptosis in heart tissues. Myocardial sections were prepared and then were incubated with $50 \mu \mathrm{L}$ TUNEL mixture at $37^{\circ} \mathrm{C}$ for $1 \mathrm{~h}$. After washing with PBS, sections were stained with DAPI. Myocardial apoptosis was observed by fluorescence microscopy. The apoptotic rate was calculated as the number of apoptotic cells (green)/the number of total cells (blue) $\times 100 \%$.

\section{Statistical analysis}

Data were presented as the mean \pm SEM. SPSS 23.0 software (SPSS, Chicago, IL, USA) was used to perform all analyses. Student's $t$-test was performed for comparison between two groups. ANOVA was used to compare with multiple groups. A $P$-value of $<0.05$ was considered statistically significant.

\section{Ethics statement}

Animal studies were performed in compliance with the ARRIVE guidelines. All animals received humane care according to the National Institutes of Health (USA) guidelines.

\section{RESULTS}

The expression of CTRP3 was downregulated in cardiomyocytes in response to $O G D / R$ conditions

To explore the role of CTRP 3 in myocardia I/R injury, we assessed the expression of CTRP 3 in $\mathrm{H} 9 \mathrm{C} 2$ cells after OGD/R treatment by using RT-qPCR and Western blotting. The results showed that the mRNA expression of CTRP3 was significantly decreased in $\mathrm{H} 9 \mathrm{C} 2$ cells in response to $\mathrm{OGD} / \mathrm{R}$ treatment (Figure $1 \mathrm{~A}, P<0.05$ ). Similarly, the protein level of CTRP3 was also remarkably restrained in $\mathrm{H} 9 \mathrm{C} 2$ cells in response to $\mathrm{OGD} / \mathrm{R}$ treatment (Figure 1B, $P<0.05$ ).

\section{CTRP3 protected against OGD/R injury in $\mathrm{H} 9 \mathrm{C2}$ cells}

To investigate the biological effect of CTRP3 in OGD/R injury, H9C2 cells were transfected with pcDNA-CTRP3 or si-CTRP3. The results of Western blotting indicated that transfection of pcDNA-CTRP3 was efficient to elevate CTRP3 protein level, and the introduction of CTRP3 siRNA caused a markedly decrease of CTRP3 level in H92C cells (Figure 2A and 2B, $P<0.05$ ). MTT and EdU assay results showed that CTRP3 
overexpression accelerated the growth of $\mathrm{H} 9 \mathrm{C} 2$ cells after OGD/R treatment, while silence of CTRP3 inhibited cell proliferation (Figure $2 \mathrm{C}-2 \mathrm{E}, P<0.05$ ). In addition, flow cytometry verified that the apoptosis ability of $\mathrm{H} 9 \mathrm{C} 2$ cells was notably suppressed after CTRP3 overexpression, while increased after CTRP3 silence (Figure 2F and 2G, $P$ $<0.05$ ). Moreover, upregulation of CTRP3 reduced ROS, MDA and cTn-I content, and silencing CTRP3 notably facilitated ROS, MDA and cTn-I production in H92C cells after $\mathrm{OGD} / \mathrm{R}$ treatment (Figure $2 \mathrm{H}-2 \mathrm{~J}, P<0.05$ ).

\section{LAMP1 was a receptor of CTRP3}

To further detect how CTRP3 participated in OGD/R injury, proteins that could interact with CTRP3 were investigated. LAMP1 has been reported to be a putative receptor of CTRP3 [22], hence, the expression of LAMP1 in $\mathrm{H} 9 \mathrm{C} 2$ cells after $\mathrm{OGD} / \mathrm{R}$ treatment was assessed. The results of RT-qPCR and Western blotting showed that the mRNA and protein levels of LAMP1 were remarkably downregulated in $\mathrm{H} 9 \mathrm{C} 2$ cells (Figure $3 \mathrm{~A}$ and $3 \mathrm{~B}, P<0.05)$. Subsequently, the interaction between CTRP3 and LAMP1 was validated by using Co-IP assay (Figure 3C). Besides, the upregulation of CTRP3 caused a significant increase of LAMP1 protein level in H9C2 cells, whereas knockdown of CTRP3 led to a opposite result (Figure 3D, $P<0.05$ ).

\section{Upregulation of LAMP1 attenuated OGD/R injury in $\mathrm{H9C2}$ cells}

Then, the effect of LAMP1 in H9C2 cells was investigated. The protein level of LAMP1 was notably

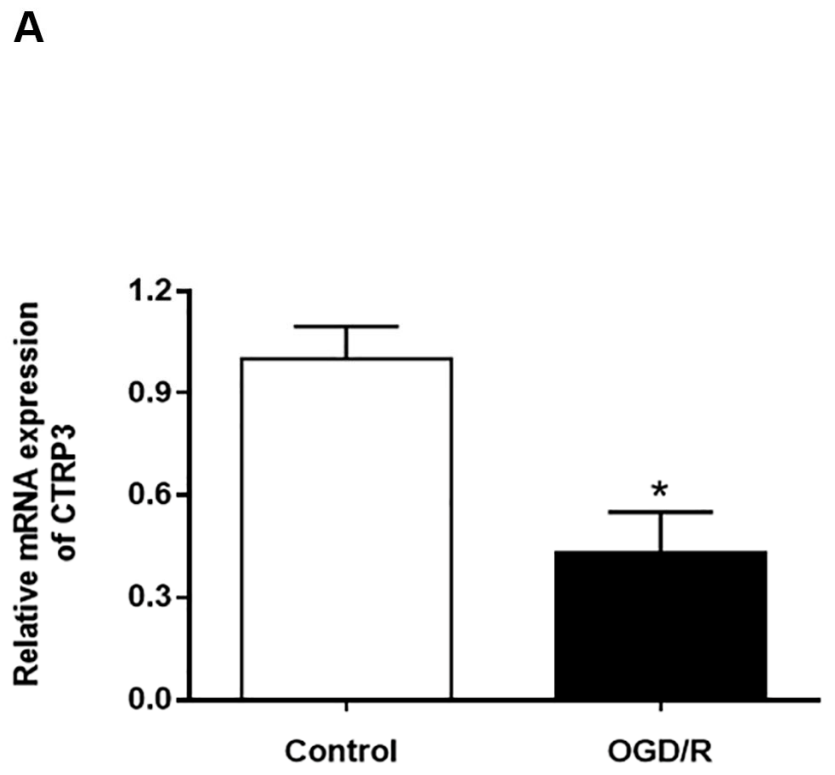

increased after $\mathrm{H} 9 \mathrm{C} 2$ cells transfected with pcDNALAMP1 compared with OGD/R treatment (Figure 4A, $P<0.05)$. LAMP1 overexpression significantly promoted cell proliferation after OGD/R injury by using MTT and EdU assays (Figure 4B and 4C, $P<0.05$ ). Moreover, cell apoptosis following OGD/R injury was conspicuously reduced by LAMP1 overexpression (Figure 4D, $P<0.05$ ). Likewise, upregulation of LAMP1 markedly cut down the production of ROS, MDA and cTn-I in H9C2 cells after OGD/R treatment (Figure $4 \mathrm{E}-4 \mathrm{G}, P<0.05$ ). These data indicated that LAMP1 overexpression improved OGD/G injury in H9C2 cells.

\section{LAMP1 overexpression abolished the biological functions of CTRP3 silence in $\mathrm{H} 9 \mathrm{C} 2$ cells}

To verify whether CTRP3 regulated the biological functions of $\mathrm{H} 9 \mathrm{C} 2$ cells dependent on LAMP1 during OGD/R injury, H9C2 cells were transfected with CTRP3 siRNA alone or together with pcDNA-LAMP1. Silencing CTRP3 significantly reduced the protein expression of LAMP1, attenuated the proliferation ability of $\mathrm{H} 9 \mathrm{C} 2$ cells, and LAMP1 overexpression reversed this alteration caused by CTRP3 knockdown (Figure 5A-5D, $P<0.05$ ). Flow cytometry analysis demonstrated that enforced expression of LAMP1 could restore the CTRP3 deficiency-mediated cell apoptosis (Figure 5E, 5F, $P<0.05$ ). Furthermore, absence of CTRP3 promoted ROS, MDA and cTn-I production in $\mathrm{H} 92 \mathrm{C}$ cells subjected to $\mathrm{OGD} / \mathrm{R}$, which was markedly countervailed by LAMP1 overexpression (Figure 5G5I, $P<0.05)$.

B
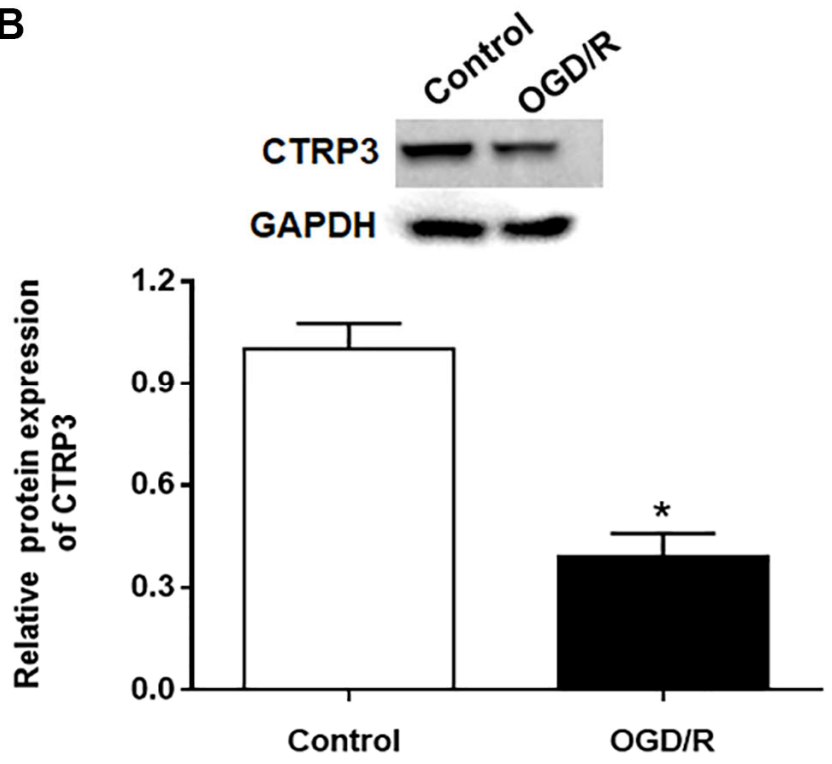

Figure 1. Effect of OGD/R treatment on CTRP3 expression in H9C2 cells. (A, B) Relative mRNA and protein expression of CTRP3 was determined by using RT-qPCR and Western blotting. ${ }^{*} p<0.05$ and the same as below. 
CTRP3 conferred its protective effects on $\mathrm{H} 9 \mathrm{C} 2$ cells via LAMP1/JIP2/JNK pathway

The JNK pathway is known to associate with myocardial $\mathrm{I} / \mathrm{R}$ injury and JNK-interacting protein-2
(JIP2) is closely related to JNK. BioGRID website (https://thebiogrid.org) and MGnify website (http://www.ebi.ac.uk/metagenomics) predicted that CTRP3 may serve as a binding partner of JIP2. Furthermore, Co-IP assay suggested that CTRP3

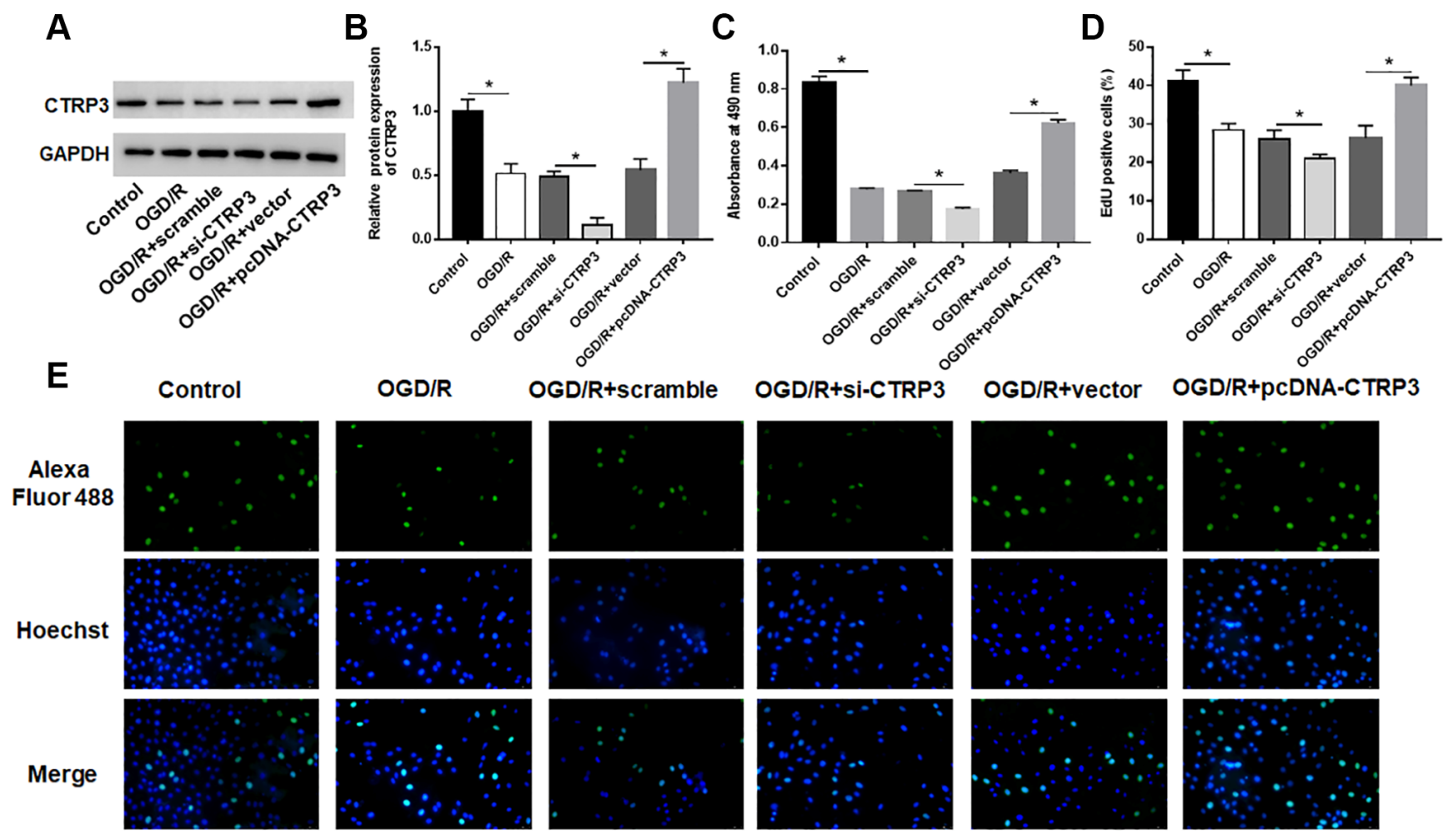

$\mathbf{F}$
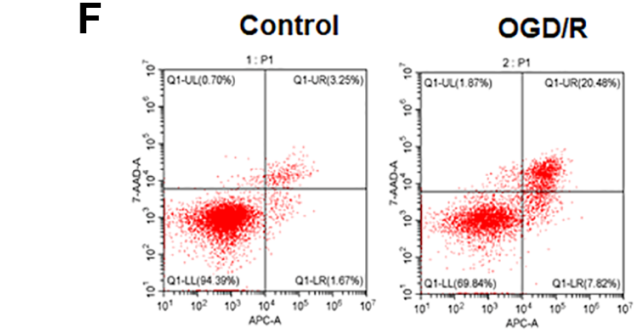

OGD/R+scramble

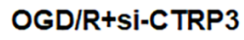

OGD/R+vector
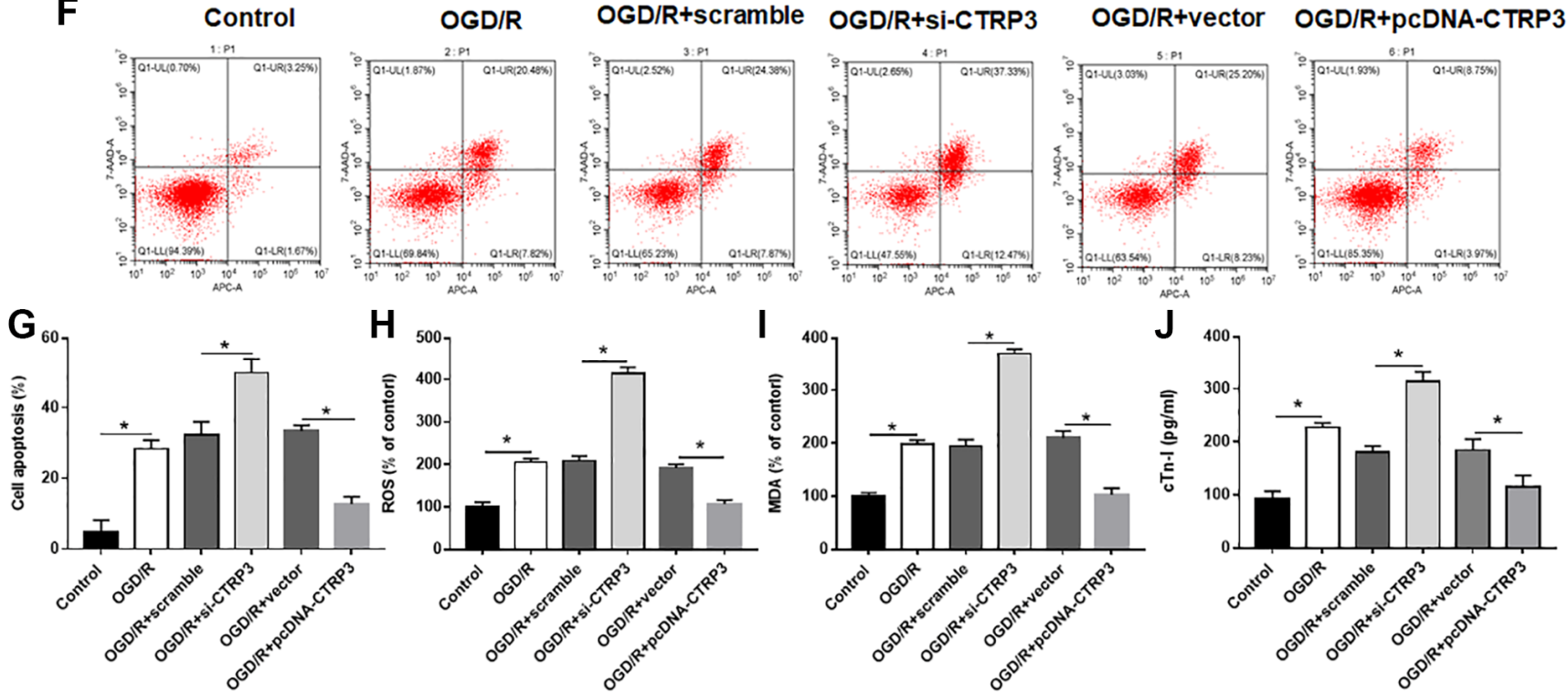

Figure 2. Effect of CTRP3 on OGD/R injury in H9C2 cells. H9C2 cells were transfected with pcDAN3.1-CTRP3 and CTRP3 siRNA or negative control (scramble and vector) to incubate for $24 \mathrm{~h}$ and then exposed to OGD/R injury. (A, B) Relative protein expression of CTRP3 was detected with Western blotting. (C-E) Effect of CTRP3 overexpression and inhibition on cell proliferation was assessed with CCK-8 and EdU assays. (F, G) Effect of CTRP3 overexpression and inhibition on cell apoptosis was detected with flow cytometry. (H-J) Effect of CTRP3 overexpression and inhibition on ROS, MDA and cTn-I production were determined. 
physically interacted with JIP2 (Figure 6A). More interestingly, the HitPredict website (http://www.hitpredict.org/) found that LAMP1 could bind to protein numb homolog (NUMB), which in turn interacted with JIP2. Co-IP confirmed the association between LAMP1, NUBM and JIP2 (Figure 6B and 6C). Subsequently, we explored the possible role of the JIP2/JNK pathway in CTRP3-related molecular events in $\mathrm{H} 9 \mathrm{C} 2$ cells during OGD/R injury. Western blot assay results showed that the protein levels of JIP2 and p-JNK were significantly reduced after $\mathrm{OGD} / \mathrm{R}$ treatment, while increased after $\mathrm{H} 9 \mathrm{C} 2$ cells transfected with pcDNA-CTRP3 and pcDNA-LAMP1 (Figure 6D-6F, $P$ $<0.05)$. Moreover, the effects of SP600125 on H9C2 cell proliferation and apoptosis were also investigated. JNK inhibitor (SP610025) reversed the promotive effects of CTRP3 or LAMP1 overexpression on the upregulation of JIP2 and p-JNK expression (Figure 6D-

A
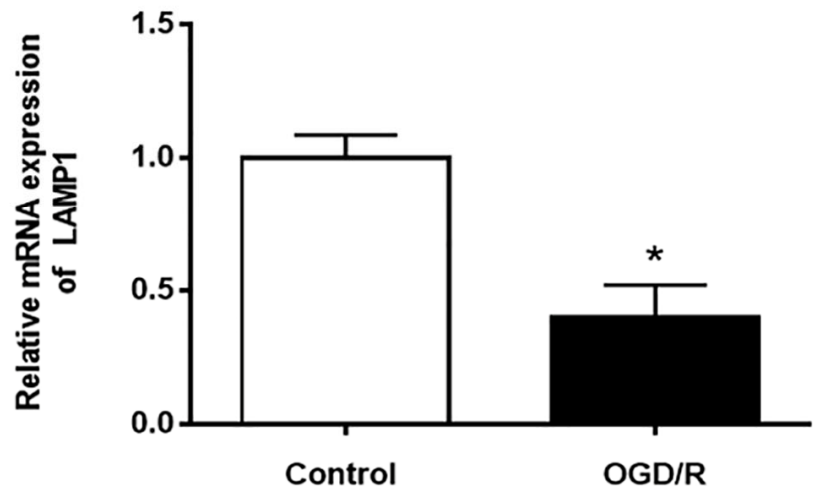

C

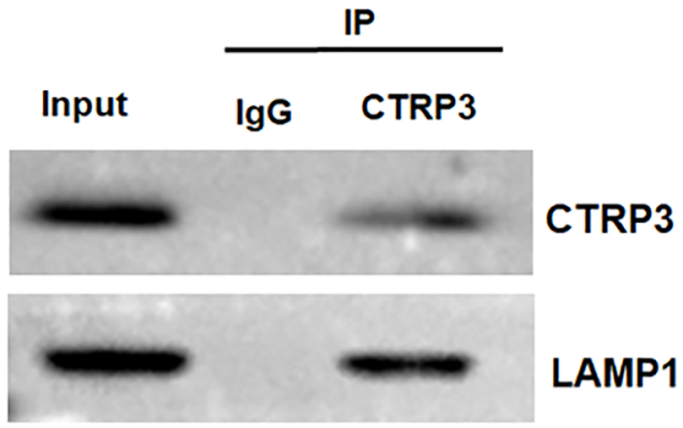

6F, $P<0.05)$. Overexpression of CTRP3 and LAMP1 effectively increased cell proliferation and decreased cell apoptosis, while SP610025 treatment could reverse these effects (Figure 6G-6K, $P<0.05$ ). These results proved that CTRP3 alleviated $\mathrm{OGD} / \mathrm{R}$ injury via LAMP1/JIP2/JNK pathway.

\section{Overexpression of CTRP3 ameliorated I/R injury}

A mouse model of myocardial I/R was established to explore the role of CTRP3 on myocardial injury. The levels of LVEF and LVFS (Figure 7A and 7B, $P<$ 0.05), and protein expression of CTRP3, LAMP1, JIP2 and p-JNK (Figure $7 \mathrm{~J}$ and $7 \mathrm{~K}, P<0.05$ ) were significantly lower in mice subjected to myocardial $\mathrm{I} / \mathrm{R}$ surgery. Moreover, myocardial infarct volume (Figure $7 \mathrm{C}$ and $7 \mathrm{D}, P<0.05$ ), apoptosis (Figure $7 \mathrm{E}$ and $7 \mathrm{~F}, P<$ 0.05 ), and the contents of ROS (Figure 7G, $P<0.05$ ),

B

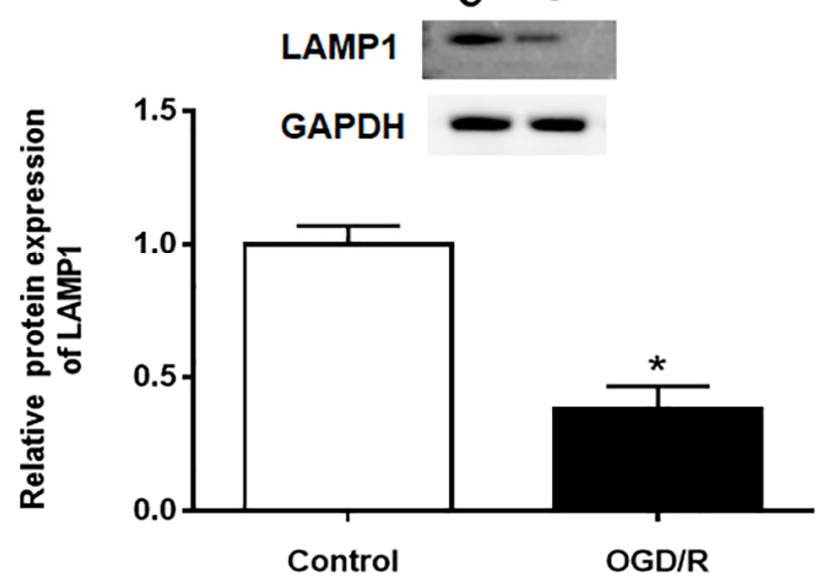

D

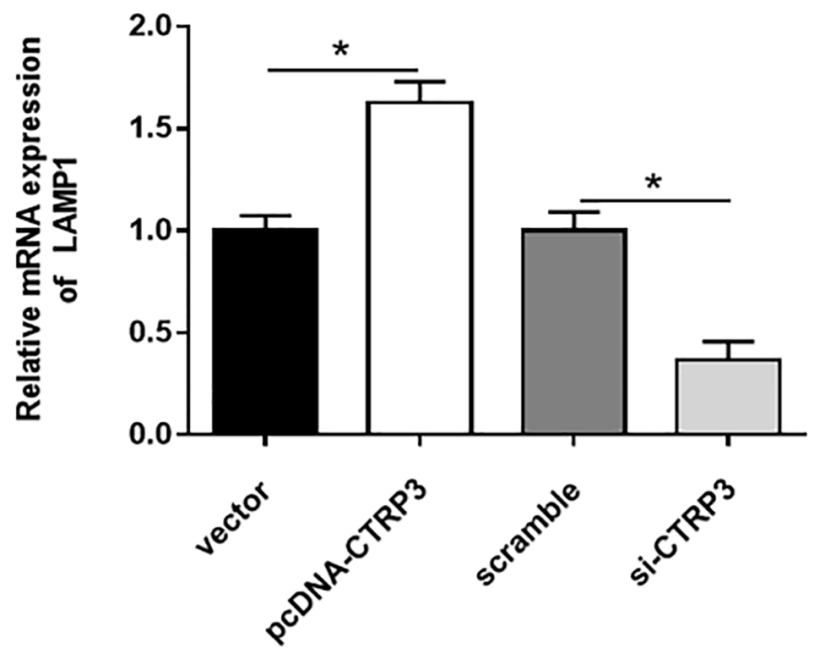

Figure 3. CTRP3 directly interacted with LAMP1. (A, B) Relative MRNA and protein expression of CTRP3 was determined by using RTqPCR and Western blotting. (C) The relationship between CTRP3 and LAMP1 was detected by using Co-IP. (D) The effects of CTRP3 silence or overexpression on the mRNA level of LAMP1 was measured by using RT-qPCR. 
MDA (Figure 7H, $P<0.05$ ) and c-Tn1 (Figure 7I, $P<$ $0.05)$ were increased after $\mathrm{I} / \mathrm{R}$ injury. However, mice injected to LV-CTRP3 could reverse the inhibitory effects of I/R injury on LVEF and LVFS levels and protein levels of CTRP3, LAMP1, JIP2 and p-JNK, and the promotive effects on myocardial infarct volume, apoptosis, and the contents of ROS, MDA and c-Tn1 ( $P$ $<0.05)$.
A
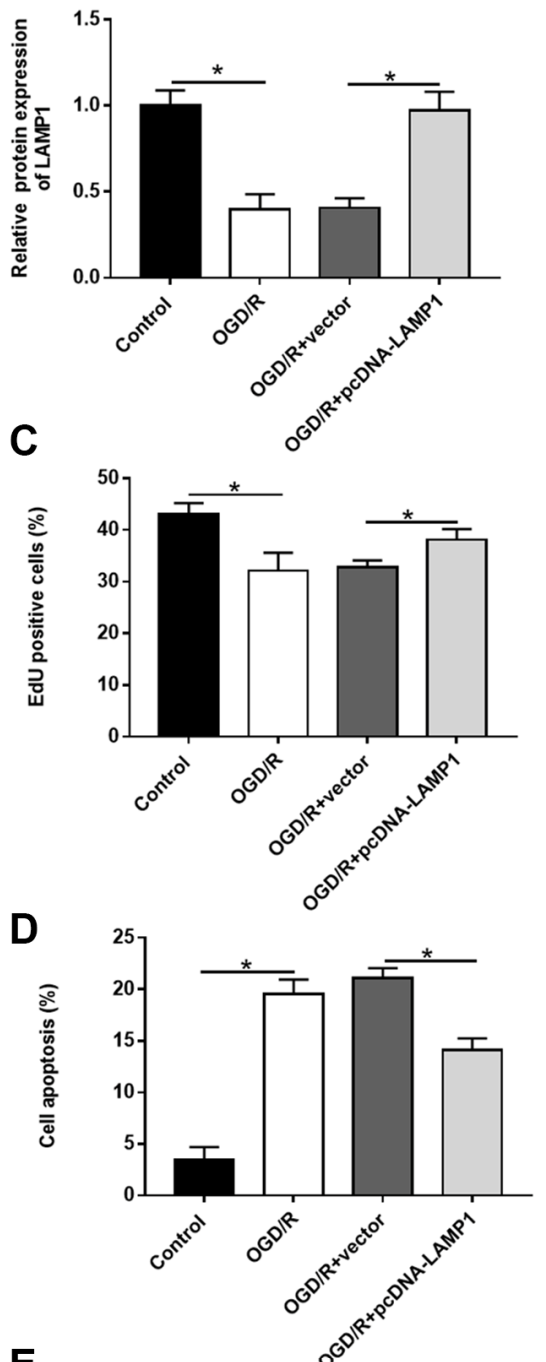

$\mathbf{E}$

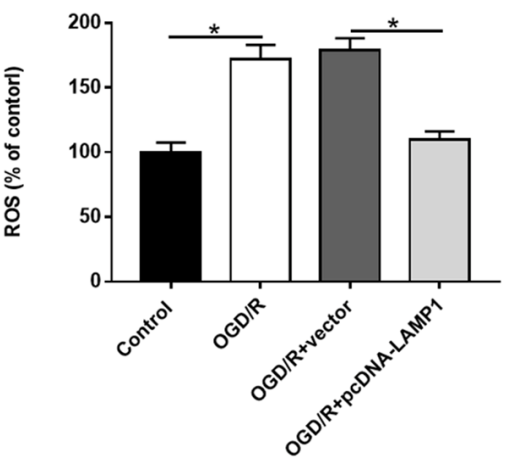

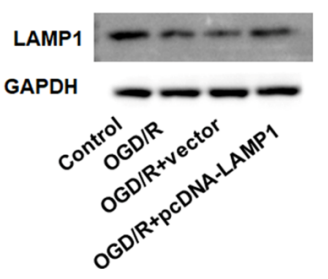

B
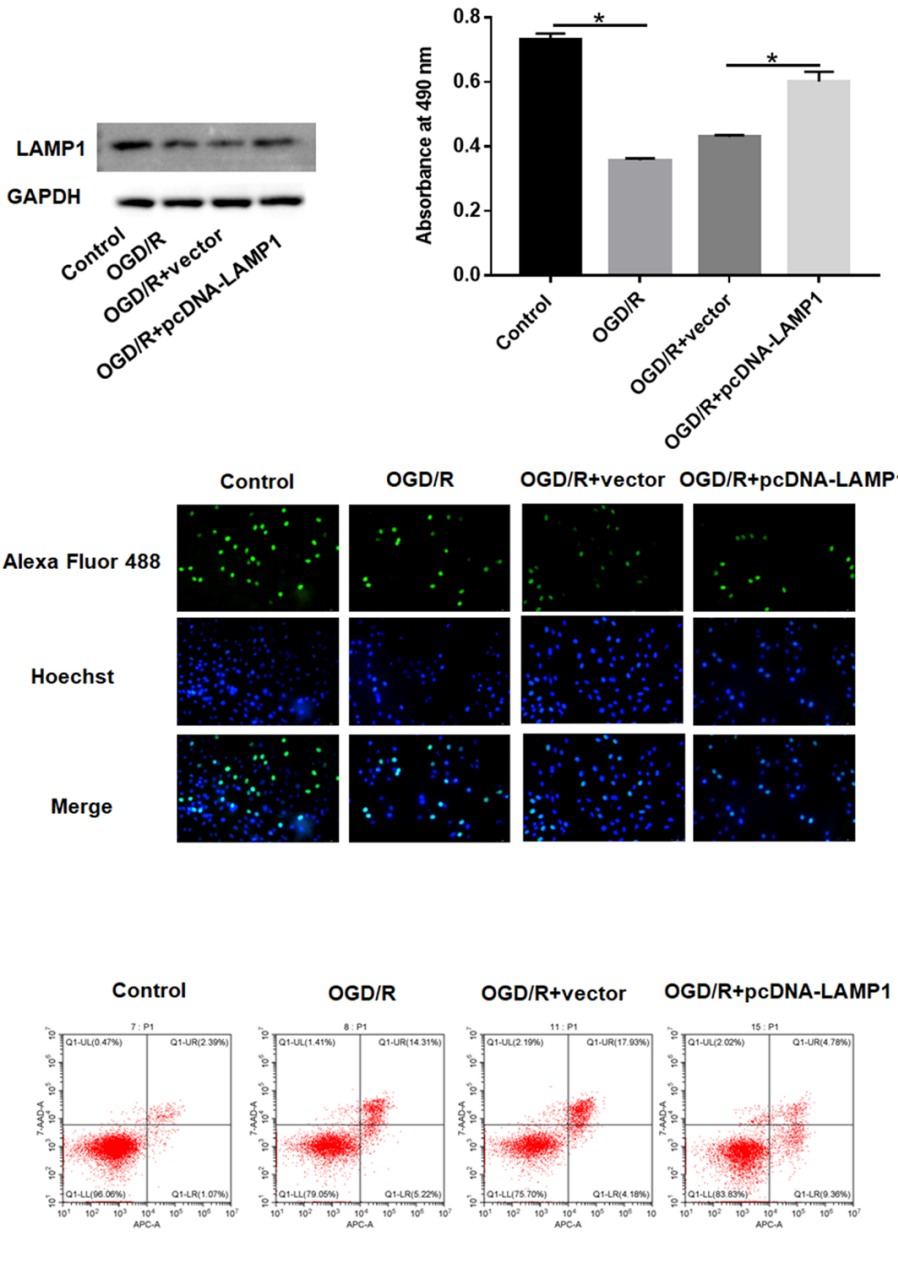

OGD/R+vector OGD/R+pcDNA-LAMP1

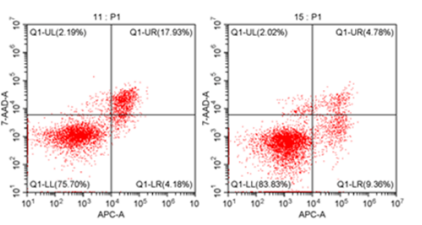

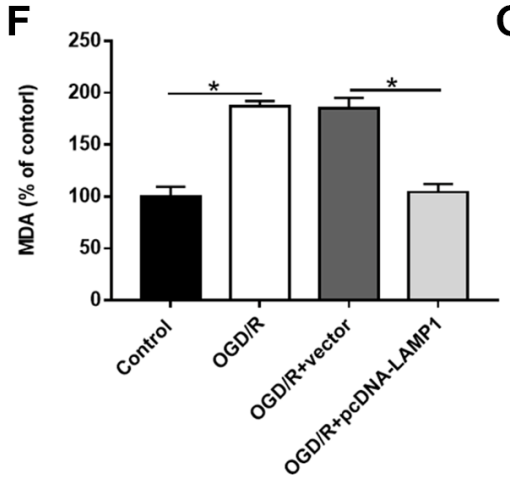

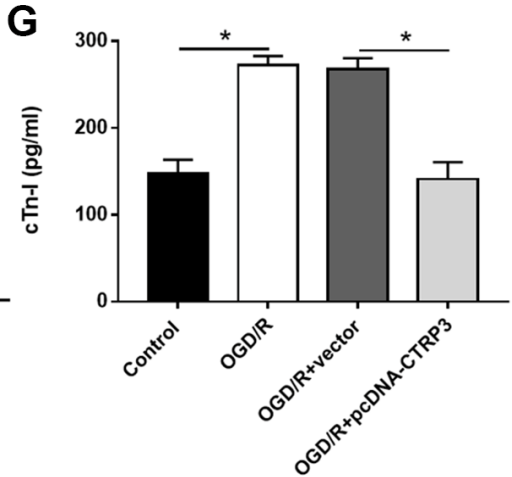

Figure 4. Effect of LAMP1 overexpression on OGD/R injury in H9C2 cells. H9C2 cells were transfected with pcDNA-LAMP1 or negative control (vector) for $24 \mathrm{~h}$ and then exposed to OGD/R injury. (A) Relative protein expression of LAMP1was detected by Western blotting. (B, C) Effect of LAMP1 overexpression on cell proliferation was assessed by using CCK-8 and EdU assays. (D) Effect of LAMP1 overexpression on cell apoptosis was detected by flow cytometry. (E-G) Effects of CTRP3 overexpression on ROS, MDA and cTn-I production were determined. 


\section{DISCUSSION}

Myocardial infarction is a severe disease associated with high mortality, and reestablishing the blood supply to the ischemic myocardial tissue is the most feasible treatment. However, prone to myocardial $\mathrm{I} / \mathrm{R}$ injury is prone to occur [23]. Previous studies have shown that myocardial infarction prevention and treatment could
A

A

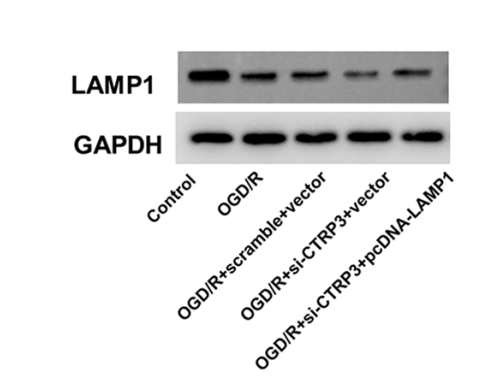

c comes
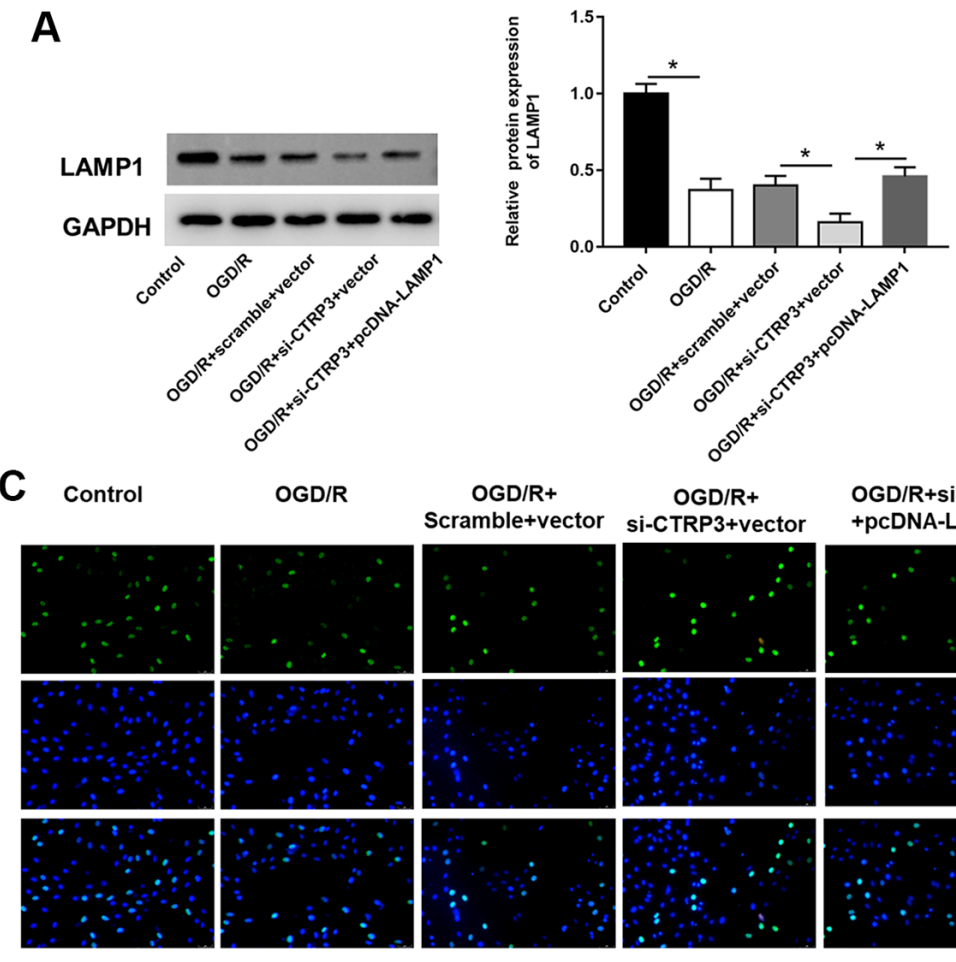

E
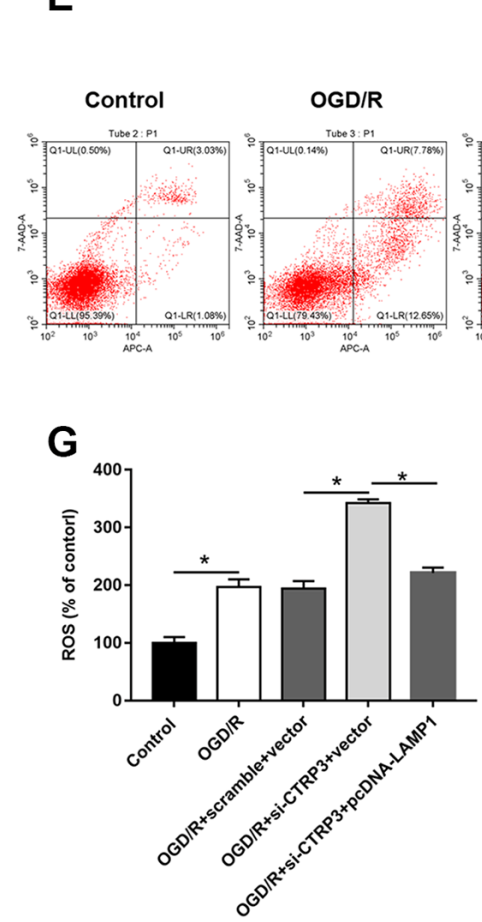

H

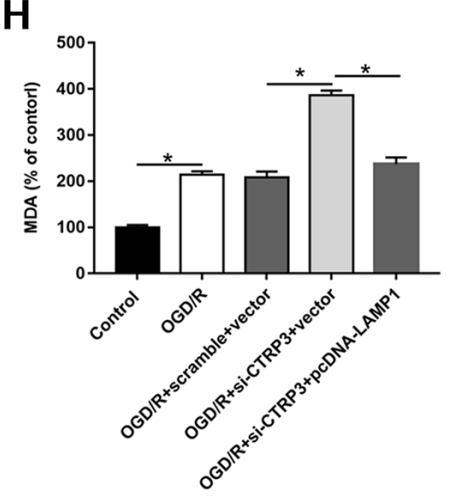

B

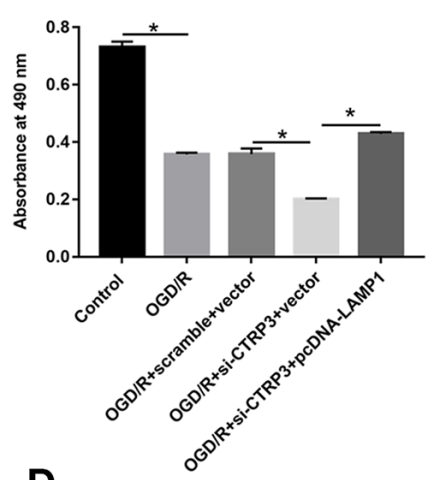

D

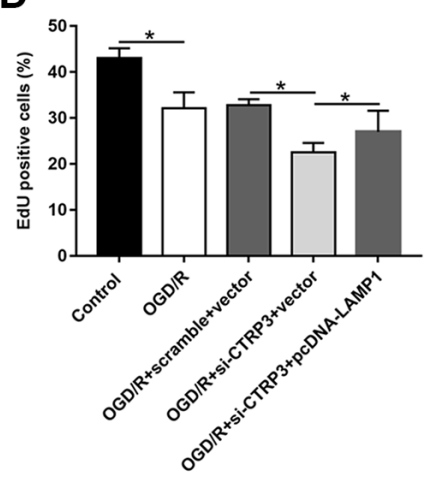

F

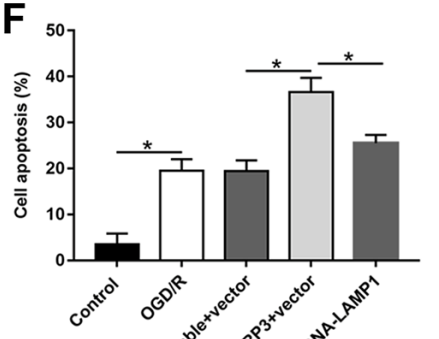

Figure 5. Overexpression of LAMP1 reversed the inhibitory effect of CTRP3 silencing on OGD/R injury in H9C2 cells. H9C2 cells were transfected with CTRP3 siRNA alone or together with pCDNA-LAMP1 for $24 \mathrm{~h}$ and then exposed to OGD/R injury. (A) The protein expression of LAMP1 was examined with Western blotting. (B-D) Cell proliferation was detected by using MTT and EdU assays. (E, F) Cell apoptosis ratio was measured by using flow cytometry. (G-I) The production of ROS, MDA and cTn-I was determined. 
target myocardial protective genes or deleterious genes or interfere with pathway gene expression, prompting the balance of protective genes and deleterious gene expression and regulating up- and downstream pathways [24]. CTRP3 was reported to be associated with the development of several heart related disorders. Overexpression of CTRP3 could enhance the therapeutic efficacy of mesenchymal stromal cells in myocardial infarction [25]. However, CTRP3 was upregulated in cardiac hypertrophy, and overexpression of CTRP3 aggravated cardiac hypertrophy and cardiac dysfunction [26]. Therefore, we speculated that the different roles of CTRP3 might be associated with the pathological process of different diseases. CTRP3 inhibited high glucose induced oxidative stress, inflammation and apoptosis, and attenuated
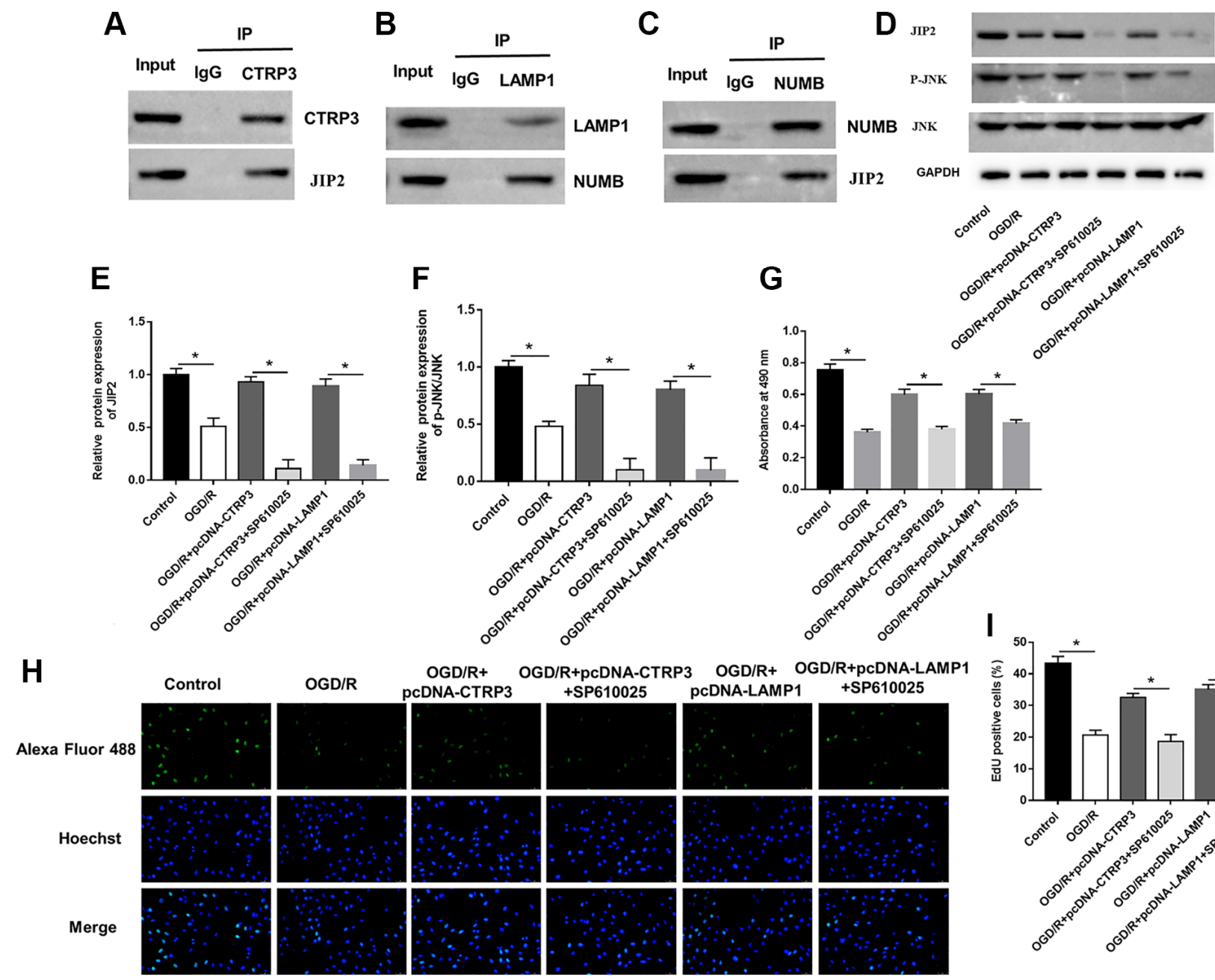

OGD/R+
CDNA-CTRP3
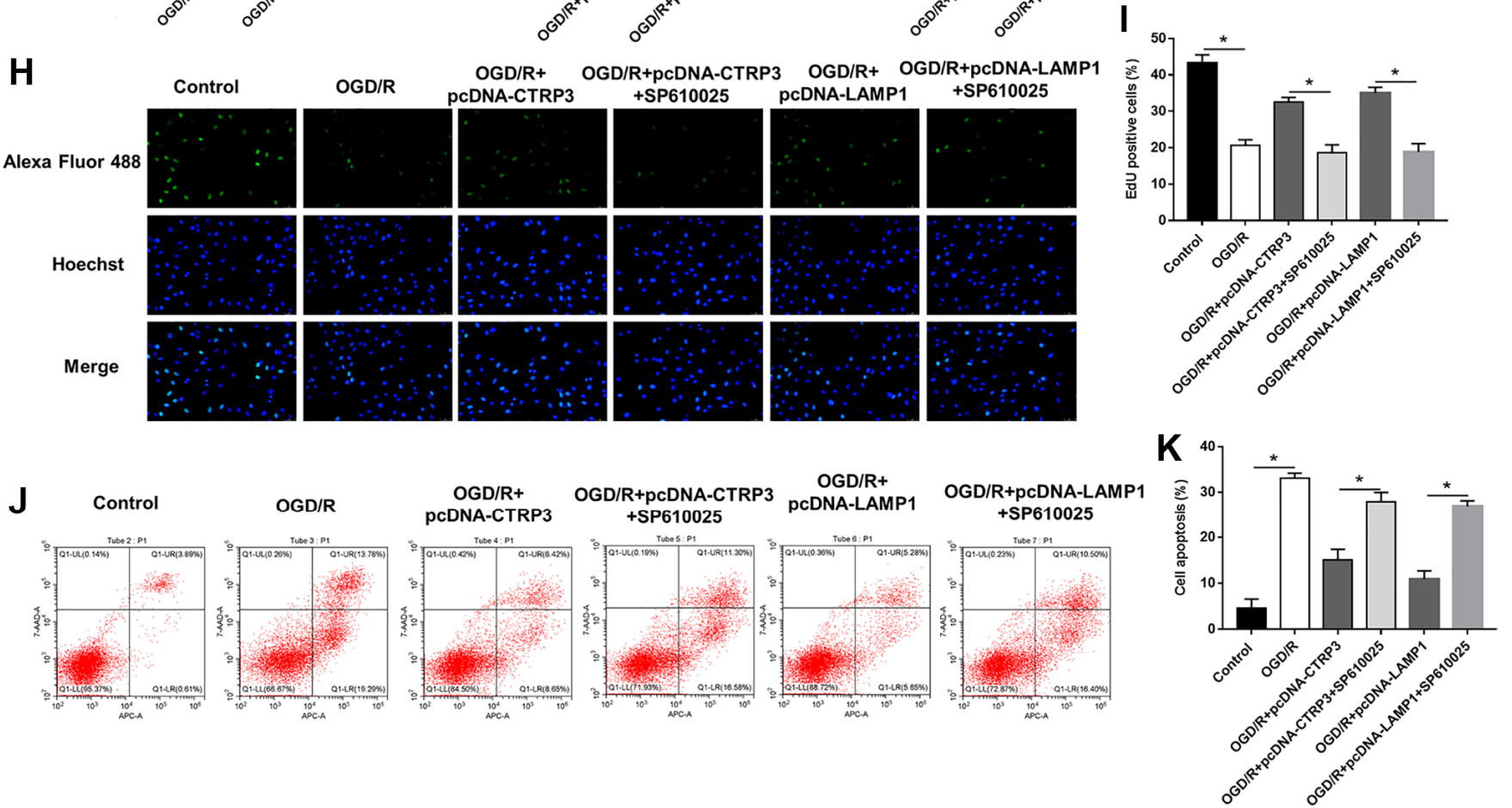

Figure 6. CTRP3 and LAMP1 overexpression accelerated activation of JIP2/JNK signaling pathway. (A) The relationship between CTRP3 and JIP2 was detected with Co-IP. (B, C) The relationships among LAMP1, NUMB and JIP2 were detected by using Co-IP. (DF) Relative protein expression of JIP2 and p-JNK was detected with Western blotting. (G-I) Cell proliferation was detected by using MTT and EdU assays. (J, K) Cell apoptosis ratio was measured by using flow cytometry. 
cardiomyocyte death and improved cardiac function in streptozotocin treated rats [15]. Zhang et al. suggested that CTRP3 was an endogenous regulator of mitochondrial biogenesis, which could protect cardiomyocytes by improving mitochondrial dysfunction [27]. In present study, CTRP3 was downregulated in $\mathrm{OGD} / \mathrm{R}$ treated $\mathrm{H} 9 \mathrm{C} 2$ cells and myocardial I/R injury mice. Overexpression of CTRP3 predominantly promoted $\mathrm{H} 9 \mathrm{C} 2$ cell proliferation and restrained apoptosis and oxidative stress, whereas CTRP3 knockdown led to opposite results, illustrating that CTRP3 played a positive role in myocardial I/R. Moreover, overexpression of CTRP3 improved left ventricular function, attenuated myocardial infarct size and apoptosis, and suppressed ROS, MDA and cTn-I levels in mice subjected to $\mathrm{I} / \mathrm{R}$ injury compared with mice in the sham group, indicating that CTRP3 has a protective effect on mice subjected to myocardial I/R injury.

Current evidence confirmed that LAMP1 was a routinely used as a lysosome marker and closely
A

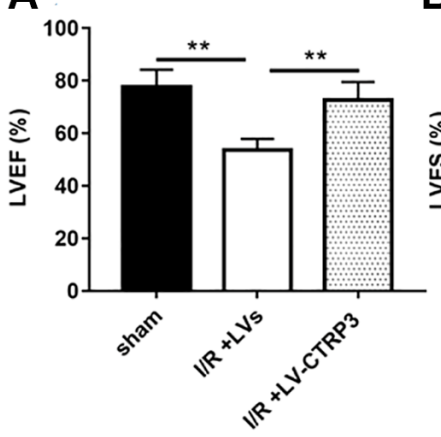

$\mathbf{E}$

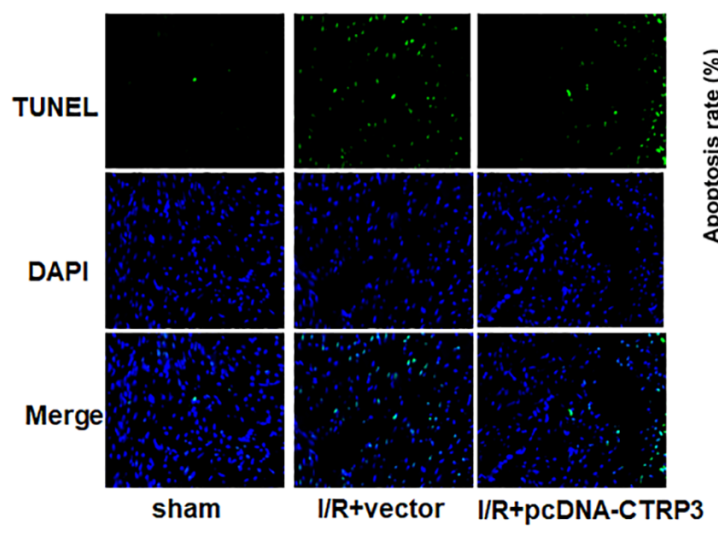

H

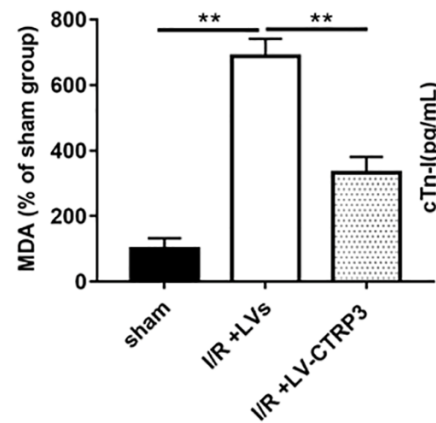

B

$F$
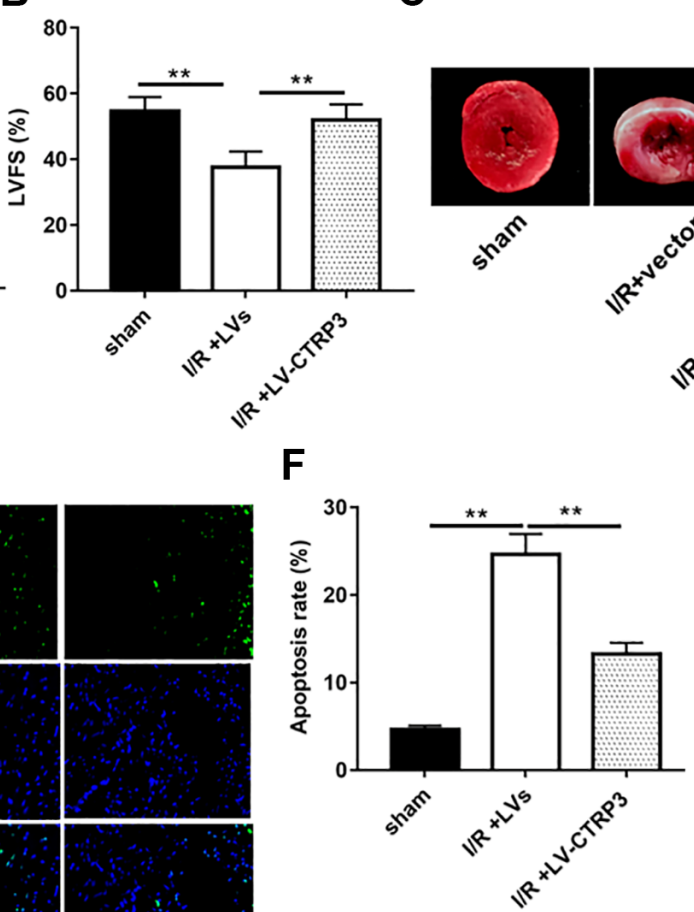

$\mathrm{J}$

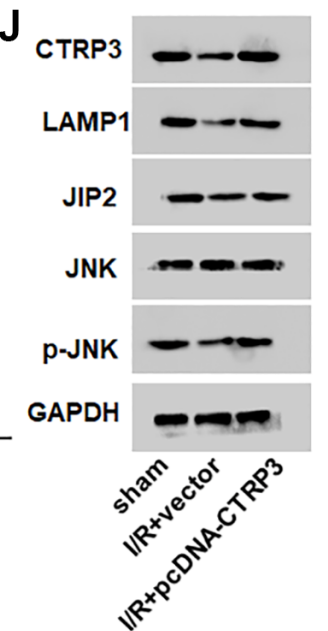

D

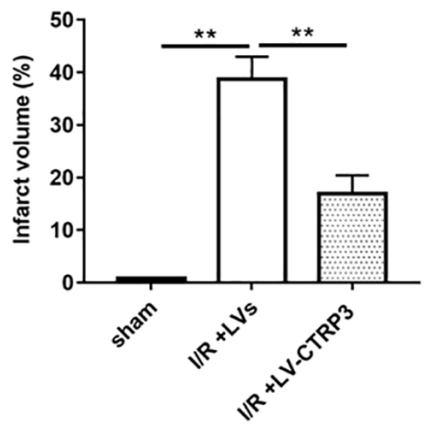

G

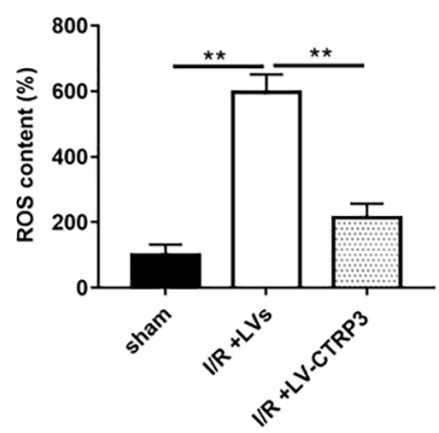

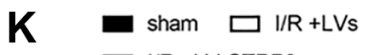

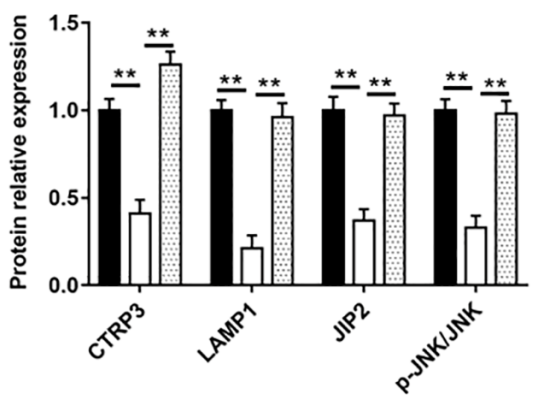

Figure 7. Overexpression of CTRP3 ameliorated I/R injury. (A, B) The levels of LVEF and LVFS were detected by echocardiograph as indexes for cardiac function at the end of the $24 \mathrm{~h}$ reperfusion. (C) Representative images of stained myocardial tissues of mice in all groups. (D) The percentage of myocardial infarction area of all groups. (E, F) Cardiomyocyte apoptosis was determined by using TUNEL assay. (G-I) The production of ROS, MDA and cTn-I was determined. (J, K) Western blotting was performed to analyze the protein expression of CTRP3, LAMPA, JIP2, JNK and p-JNK in myocardial tissue. 
correlated with autophagy [28]. Upregulation of LAMP1 could form autolysosomes and accelerate ROS removal, thus inhibiting oxidative stress [29]. It is well known that excessive superoxide mediated oxidative stress and autophagy plays an important role in myocardial injury [30], suggesting that LAMP1 may be a key player in cardiomyocytes. Hence, whether CTRP3 and LAMP1 are related needs to be discussion. Studies found that CTRP3 directly inhibited the inflammatory response of psoriatic keratinocytes in vitro by blocking the phosphorylation of signal transducer and activator of transcription 3 by LAMP1 [31]. Our study revealed that CTRP3 attenuated apoptosis and oxidative stress in H9C2 cells after $\mathrm{OGD} / \mathrm{R}$ stimulation via upregulating LAMP1. Next, Co-IP assay was performed to validate the relationship between CTRP3 and LAMP1. Results as we speculated, CTRP3 ameliorated myocardial injury caused by OGD/R treatment via LAMP1. Overexpression of LAMP1 remarkably reversed the inhibitory effects of CTRP3 silence on $\mathrm{H} 9 \mathrm{C} 2$ cell proliferation, and the promotive effects on cell apoptosis and oxidative stress.

NUMB plays an important role in cardiac progenitor cell differentiation and cardiac morphogenesis and serves as a potential candidate gene for cardiac regeneration and treatment of congenital heart disease $[32,33]$. Mitogen-activated protein kinase (MAPK) signaling pathway is associated with multiple cardiac diseases, including cardiac fibrosis, myocardial $\mathrm{I} / \mathrm{R}$ injury [34]. JIP2 is a key scaffolding protein that promotes the activity of MAPK pathway proteins, including JNKs, and plays an important role in myocardial $\mathrm{I} / \mathrm{R}$ injury [35]. NUNB acts as an intermediate connector protein of LAMP1 regulating the JIP2/JNK pathway. In addition, CTRP3 also protects against myocardial $\mathrm{I} / \mathrm{R}$ injury by interacting with JIP2.

JNK pathway was involved in cellular fate such as proliferation, migration, invasion and apoptosis [36, 37]. However, the role of JNK pathway in myocardial $\mathrm{I} / \mathrm{R}$ injury is controversial. Tumor necrosis factor receptor-associated factor 1 (TRAF1) aggravated the development of myocardial I/R injury by enhancing the activation of the JNK pathway [38]. However, alamandine pretreatment alleviates pathological alterations and cell injury in myocardium by activating JNK phosphorylation [39]. Cao et al. showed that activation of JNK increased the expression of heme oxygenase-1 (HO-1), which could reduce ROS-induced cell death in myocardial $\mathrm{I} / \mathrm{R}$ injury [40]. Our results suggested that overexpression of CTRP 3 or LAMP1 increased JIP2 and p-JNK protein levels in $\mathrm{H} 9 \mathrm{C} 2$ cells after $\mathrm{OGD} / \mathrm{R}$ treatment, thereby activating JIP $2 / \mathrm{JNK}$ pathway to promote $\mathrm{H} 9 \mathrm{C} 2$ cell proliferation and suppress cell apoptosis, which could be abolish by SP600125.

\section{CONCLUSION}

In conclusion, the present study highlighted the protective roles of CTRP3 in myocardial I/R injury, manifested by promoting cell proliferation and suppressing cell apoptosis and oxidative stress via upregulating LAMP1 and activating JIP2/JNK signaling pathway. Therefore, CTRP3 may be a promising therapeutic target for the treatment of myocardial $I / R$ injury.

\section{AUTHOR CONTRIBUTIONS}

YB Song designed the study and draft the original manuscript; YQ Zhang performed the study and draft the original manuscript; ZF Wan prepared the figures and reviewed the manuscript; JQ Pan and F Gao analyzed the data, performed the statistical analysis, and reviewed the manuscript; F Li, J Zhou, and JM Chen provided part of the resources and reviewed the manuscript.

\section{CONFLICTS OF INTEREST}

The authors declare no conflicts of interest related to this study.

\section{FUNDING}

This study was supported by the National Natural Science Foundation of China (Grant No.81760069 and 81960080), Special Talents Program of Shaanxi Province (2019; Grant No.00574), Technology Innovation Team of CTRP3 protects myocardial ischemia/reperfusion injury, Yan'an, 2019.

\section{REFERENCES}

1. O'Gara PT, Kushner FG, Ascheim DD, Casey DE Jr, Chung MK, de Lemos JA, Ettinger SM, Fang JC, Fesmire FM, Franklin BA, Granger CB, Krumholz HM, Linderbaum JA, et al. 2013 ACCF/AHA guideline for the management of ST-elevation myocardial infarction: a report of the American College of Cardiology Foundation/American Heart Association Task Force on Practice Guidelines. J Am Coll Cardiol. 2013; 61:e78-140.

https://doi.org/10.1016/i.jacc.2012.11.019

PMID:23256914

2. Lu L, Ma J, Tang J, Liu Y, Zheng Q, Chen S, Gao E, Ren J, Yang L, Yang J. Irisin attenuates myocardial ischemia/reperfusion-induced cardiac dysfunction by 
regulating ER-mitochondria interaction through a mitochondrial ubiquitin ligase-dependent mechanism. Clin Transl Med. 2020; 10:e166.

https://doi.org/10.1002/ctm2.166

PMID:32997406

3. Wu S, Chang G, Gao L, Jiang D, Wang L, Li G, Luo X, Qin S, Guo X, Zhang D. Trimetazidine protects against myocardial ischemia/reperfusion injury by inhibiting excessive autophagy. J Mol Med (Berl). 2018; 96:791806.

https://doi.org/10.1007/s00109-018-1664-3

PMID:29955901

4. Ding S, Yang Y, Mei J. Protective Effects of L-Malate against Myocardial Ischemia/Reperfusion Injury in Rats. Evid Based Complement Alternat Med. 2016; 2016:3803657.

https://doi.org/10.1155/2016/3803657 PMID:26941825

5. Zhao ZQ. Oxidative stress-elicited myocardial apoptosis during reperfusion. Curr Opin Pharmacol. 2004; 4:159-65.

https://doi.org/10.1016/i.coph.2003.10.010 PMID: 15063360

6. Otani M, Furukawa S, Wakisaka S, Maeda T. A novel adipokine C1q/TNF-related protein 3 is expressed in developing skeletal muscle and controls myoblast proliferation and differentiation. Mol Cell Biochem. 2015; 409:271-82.

https://doi.org/10.1007/s11010-015-2531-y PMID:26272338

7. Yi W, Sun $Y$, Yuan $Y$, Lau WB, Zheng $Q$, Wang $X$, Wang $Y$, Shang X, Gao E, Koch WJ, Ma XL. C1q/tumor necrosis factor-related protein-3, a newly identified adipokine, is a novel antiapoptotic, proangiogenic, and cardioprotective molecule in the ischemic mouse heart. Circulation. 2012; 125:3159-69. https://doi.org/10.1161/CIRCULATIONAHA.112.0999 $\underline{37}$ PMID:22653084

8. Nishimoto $\mathrm{H}$, Yamamoto A, Furukawa $\mathrm{S}$, Wakisaka $\mathrm{S}$, Maeda T. C1q/TNF-related protein 3 expression and effects on adipocyte differentiation of 3T3-L1 cells. Cell Biol Int. 2017; 41:197-203.

https://doi.org/10.1002/cbin.10674 PMID:27590487

9. Hu TY, Li LM, Pan YZ. CTRP3 inhibits high glucoseinduced human glomerular mesangial cell dysfunction. J Cell Biochem. 2019; 120:5729-36. https://doi.org/10.1002/jcb.27859 PMID: $\underline{30362596}$

10. Zhang R, Zhong L, Zhou J, Peng Y. Complement-C1q TNF-Related Protein 3 Alleviates Mesangial Cell
Activation and Inflammatory Response Stimulated by Secretory IgA. Am J Nephrol. 2016; 43:460-8.

https://doi.org/10.1159/000446353

PMID:27309491

11. Petersen PS, Wolf RM, Lei X, Peterson JM, Wong GW. Immunomodulatory roles of CTRP3 in endotoxemia and metabolic stress. Physiol Rep. 2016; 4:e12735.

https://doi.org/10.14814/phy2.12735

PMID:26997632

12. Lv $C$, He $Y$, Wei $M, X u G$, Chen $C, X u Z$, Ding Z. CTRP3 ameliorates cerulein-induced severe acute pancreatitis in mice via SIRT1/NF-KB/p53 axis. Biosci Rep. 2020; 40:BSR20200092. https://doi.org/10.1042/BSR20200092 PMID: $\underline{2219332}$

13. Zhang J, He J. CTRP3 inhibits high glucose-induced oxidative stress and apoptosis in retinal pigment epithelial cells. Artif Cells Nanomed Biotechnol. 2019; 47:3758-64.

https://doi.org/10.1080/21691401.2019.1666864 PMID:31556307

14. Meng J, Wang DM, Luo LL. CTRP3 acts as a novel regulator in depressive-like behavior associated inflammation and apoptosis by meditating p38 and JNK MAPK signaling. Biomed Pharmacother. 2019; 120:109489.

https://doi.org/10.1016/i.biopha.2019.109489 PMID:31629950

15. Ma ZG, Yuan YP, Xu SC, Wei WY, Xu CR, Zhang X, Wu $\mathrm{QQ}$, Liao HH, Ni J, Tang QZ. CTRP3 attenuates cardiac dysfunction, inflammation, oxidative stress and cell death in diabetic cardiomyopathy in rats. Diabetologia. 2017; 60:1126-37. https://doi.org/10.1007/s00125-017-4232-4 PMID: $\underline{28258411}$

16. Chen L, Qin L, Liu X, Meng X. CTRP3 Alleviates Ox-LDLInduced Inflammatory Response and Endothelial Dysfunction in Mouse Aortic Endothelial Cells by Activating the PI3K/Akt/eNOS Pathway. Inflammation. 2019; 42:1350-9. https://doi.org/10.1007/s10753-019-00996-1 PMID: $\underline{30887395}$

17. Alessandrini F, Pezzè L, Ciribilli Y. LAMPs: Shedding light on cancer biology. Semin Oncol. 2017; 44:239-53. https://doi.org/10.1053/i.seminoncol.2017.10.013 PMID:29526252

18. Yu C, Longfei L, Long W, Feng Z, Chen J, Chao L, Peihua L, Xiongbing Z, Hequn C. LncRNA PVT1 regulates VEGFC through inhibiting miR-128 in bladder cancer cells. J Cell Physiol. 2019; 234:1346-53.

https://doi.org/10.1002/icp.26929

PMID: $\underline{30076714}$ 
19. Sanmarco LM, Wheeler MA, Gutiérrez-Vázquez C, Polonio CM, Linnerbauer M, Pinho-Ribeiro FA, Li Z, Giovannoni F, Batterman KV, Scalisi G, Zandee SEJ, Heck ES, Alsuwailm $M$, et al. Gut-licensed IFN ${ }^{+} N K$ cells drive LAMP1 $^{+}$TRAIL $^{+}$anti-inflammatory astrocytes. Nature. 2021; 590:473-9.

https://doi.org/10.1038/s41586-020-03116-4

PMID:33408417

20. Wang X, Li C, Wang Q, Li W, Guo D, Zhang X, Shao M, Chen X, Ma L, Zhang $Q$, Wang W, Wang Y. Tanshinone IIA Restores Dynamic Balance of Autophagosome/Autolysosome in DoxorubicinInduced Cardiotoxicity via Targeting Beclin1/LAMP1. Cancers (Basel). 2019; 11:910.

https://doi.org/10.3390/cancers11070910 PMID: $\underline{1261758}$

21. Li J, Xiang $X, X u$ Z. Cilostazol protects against myocardial ischemia and reperfusion injury by activating transcription factor EB (TFEB). Biotechnol Appl Biochem. 2019; 66:555-63.

https://doi.org/10.1002/bab.1754

PMID:30994947

22. Li Y, Ozment T, Wright GL, Peterson JM. Identification of Putative Receptors for the Novel Adipokine CTRP3 Using Ligand-Receptor Capture Technology. PLoS One. 2016; 11:e0164593.

https://doi.org/10.1371/journal.pone.0164593 PMID:27727322

23. Zong L, Wang W. CircANXA2 Promotes Myocardial Apoptosis in Myocardial Ischemia-Reperfusion Injury via Inhibiting miRNA-133 Expression. Biomed Res Int. 2020; 2020:8590861.

https://doi.org/10.1155/2020/8590861 PMID: $\underline{32685535}$

24. Huang W, Yang J, He C, Yang J. RP105 plays a cardioprotective role in myocardial ischemia reperfusion injury by regulating the Toll-like receptor 2/4 signaling pathways. Mol Med Rep. 2020; 22:1373-81.

https://doi.org/10.3892/mmr.2020.11242

PMID: $\underline{32626996}$

25. Zhang Z, Zhu L, Feng P, Tan Y, Zhang B, Gao E, Wang $X$, Fan C, Wang X, Yi W, Sun Y. C1q/tumor necrosis factor-related protein-3-engineered mesenchymal stromal cells attenuate cardiac impairment in mice with myocardial infarction. Cell Death Dis. 2019; 10:530.

https://doi.org/10.1038/s41419-019-1760-5

PMID:31296837

26. Ma ZG, Yuan YP, Zhang X, Xu SC, Kong CY, Song P, Li $\mathrm{N}$, Tang QZ. C1q-tumour necrosis factor-related protein-3 exacerbates cardiac hypertrophy in mice. Cardiovasc Res. 2019; 115:1067-77. https://doi.org/10.1093/cvr/cvy279

PMID:30407523

27. Zhang $\mathrm{CL}$, Feng $\mathrm{H}$, Li L, Wang JY, Wu D, Hao YT, Wang Z, Zhang Y, Wu LL. Globular CTRP3 promotes mitochondrial biogenesis in cardiomyocytes through AMPK/PGC-1 $\alpha$ pathway. Biochim Biophys Acta Gen Subj. 2017; 1861:3085-94.

https://doi.org/10.1016/i.bbagen.2016.10.022

PMID:27793739

28. Cheng $X T$, Xie YX, Zhou B, Huang N, Farfel-Becker $T$, Sheng ZH. Revisiting LAMP1 as a marker for degradative autophagy-lysosomal organelles in the nervous system. Autophagy. 2018; 14:1472-4.

https://doi.org/10.1080/15548627.2018.1482147 PMID:29940787

29. Zhao F, Wang J, Lu H, Fang L, Qin H, Liu C, Min W. Neuroprotection by Walnut-Derived Peptides through Autophagy Promotion via Akt/mTOR Signaling Pathway against Oxidative Stress in PC12 Cells. J Agric Food Chem. 2020; 68:3638-48.

https://doi.org/10.1021/acs.jafc.9b08252 PMID:32090563

30. Xiang H, Yang J, Li J, Yuan L, Lu F, Liu C, Tang Y. Citrate pretreatment attenuates hypoxia/reoxygenationinduced cardiomyocyte injury via regulating microRNA-142-3p/Rac1 aix. J Recept Signal Transduct Res. 2020; 40:560-9.

https://doi.org/10.1080/10799893.2020.1768548 PMID: $\underline{2456513}$

31. Xue K, Shao S, Fang H, Ma L, Li C, Lu Z, Wang G. Adipocyte-Derived CTRP3 Exhibits Anti-Inflammatory Effects via LAMP1-STAT3 Axis in Psoriasis. J Invest Dermatol. 2021. [Epub ahead of print]. https://doi.org/10.1016/j.jid.2021.09.027 PMID:34687744

32. Zhao C, Guo H, Li J, Myint T, Pittman W, Yang L, Zhong W, Schwartz RJ, Schwarz JJ, Singer HA, Tallquist MD, Wu M. Numb family proteins are essential for cardiac morphogenesis and progenitor differentiation. Development. 2014; 141:281-95. https://doi.org/10.1242/dev.093690 PMID:24335256

33. Wu M, Li J. Numb family proteins: novel players in cardiac morphogenesis and cardiac progenitor cell differentiation. Biomol Concepts. 2015; 6:137-48. https://doi.org/10.1515/bmc-2015-0003 PMID:25883210

34. Li D, Mao C, Zhou E, You J, Gao E, Han Z, Fan Y, He Q, Wang C. MicroRNA-21 Mediates a Positive Feedback on Angiotensin II-Induced Myofibroblast Transformation. J Inflamm Res. 2020; 13:1007-20. https://doi.org/10.2147/JIR.S285714 PMID:33273841 
35. Li HW, Xiao FY. Effect of hydrogen sulfide on cardiomyocyte apoptosis in rats with myocardial ischemia-reperfusion injury via the JNK signaling pathway. Eur Rev Med Pharmacol Sci. 2020; 24:2054-61.

https://doi.org/10.26355/eurrev 202002_20383

PMID:32141574

36. Xu F, Xu F, Xie S, Zuo W, Wen G, Zhao T, Wan X. MicroRNA-448 overexpression inhibits fibroblast proliferation and collagen synthesis and promotes cell apoptosis via targeting $A B C C 3$ through the JNK signaling pathway. J Cell Physiol. 2020; 235:1374-85. https://doi.org/10.1002/jcp.29056 PMID:31506947

37. Ran A, Guan L, Wang J, Wang Y. GREM2 maintains stem cell-like phenotypes in gastric cancer cells by regulating the JNK signaling pathway. Cell Cycle. 2019; 18:2414-31.

https://doi.org/10.1080/15384101.2019.1646561

PMID:31345097
38. Xu W, Zhang L, Zhang $\mathrm{Y}$, Zhang $\mathrm{K}, \mathrm{Wu} \mathrm{Y}$, Jin D. TRAF1 Exacerbates Myocardial Ischemia Reperfusion Injury via ASK1-JNK/p38 Signaling. J Am Heart Assoc. 2019; 8:e012575.

https://doi.org/10.1161/JAHA.119.012575

PMID:31650881

39. Song XD, Feng JP, Yang RX. Alamandine protects rat from myocardial ischemia-reperfusion injury by activating JNK and inhibiting NF-KB. Eur Rev Med Pharmacol Sci. 2019; 23:6718-26.

https://doi.org/10.26355/eurrev 20190818563

PMID:31378915

40. Cao H, Wang $Y$, Wang $Q$, Wang $R$, Guo S, Zhao X, Zhang $Y$, Tong $D$, Yang Z. Taxol prevents myocardial ischemia-reperfusion injury by inducing JNK-mediated HO-1 expression. Pharm Biol. 2016; 54:555-60.

PMID:26270131 